\title{
Usefulness of clinical features and liver biopsy in diagnosis of disseminated herpes simplex infection
}

\author{
J RAGA, V CHRYSTAL, AND H M COOVADIA \\ Departments of Paediatrics and Child Health and Anatomical Pathology, Faculty of Medicine, University of \\ Natal, South Africa
}

SUMMARY With the advent of effective antiviral treatment for disseminated herpes infection it has become important to be able to make a firm clinical diagnosis of this condition. We undertook a retrospective analysis of 20 patients with disseminated herpes simplex infection diagnosed at necropsy to derive useful clinical pointers to this severe form of the disease. The most useful clinical criteria were malnutrition, post measles state, and local herpes infection in addition to encephalopathy, enlarging hepatomegaly, and deteriorating pneumonia. The liver showed characteristic histological changes in 18 of 19 patients. These clinical criteria combined with liver biopsy were applied in a prospective pilot study of five patients at risk for disseminated herpes infection and the results were encouraging.

Herpes simplex virus is a common parasite of man usually causing mild to moderate irritation, but under certain conditions it results in serious disease. Disseminated disease $\mathrm{e}^{1-3}$ is seen mainly in those with postulated defects of cell mediated immunity, as for example the newborn, severely malnourished children ${ }^{4-6}$ children with post measles state, ${ }^{7}$ persons with skin diseases, and after organ transplantation. ${ }^{89}$ The central problem in herpes is early recognition of the escape of infection from localised restricted lesions to generalised disease. The recent introduction of relatively safe and effective drugs for this virus has emphasised the need for a sharper definition of the clinical picture of disseminated herpes.

Among children in developing countries it is the presence of malnutrition and measles, either singly or in combination, which predisposes to severe herpes, carrying with it a high morbidity and mortality. Although clinical features which should alert the physician to the spread of herpes infection have been indicated in these children, ${ }^{3}$ dissemination may be extremely difficult to diagnose and is known to occur in the absence of local lesions.

We undertook a retrospective analysis of 20 patients with disseminated herpes simplex diagnosed at necropsy to derive useful pointers to this severe form of the disease. These criteria were then used as a basis for diagnosis in a prospective pilot study of disseminated herpes infection.

\section{Subjects}

Retrospective necropsy study. The records of chipe dren admitted to the Department of Paediatrics and Child Health and entered into the Department of Pathology, King Edward VIII Hospital, Durban between 1972 and 1981 in whom a diagnosis of disseminated herpes virus infection had been made at necropsy, were analysed retrospectively. The aim was to define clinical features and pathological findings in this condition.

Prospective pilot study. Clinical and pathological criteria derived from the previous study were used to diagnose and treat disseminated herpes simplex infection in those children at risk from the disease admitted to the King Edward VIII Hospital, Durban between 1981 and 1983 .

\section{Results}

\section{Retrospective necropsy study}

Clinical details

There were 20 African patients (11 girls and 9 boys) ranging in age from 2 to 48 months with a mean of 16.25 months. Fifteen patients had evidence of protein-energy malnutrition (kwashiorkor (11), marasmus (two), marasmic kwashiorkor (one), and underweight (one)) and four were post measles. In two patients the post measles state and kwashiorkor 
coexisted. The temperature was raised (greater than $38^{\circ} \mathrm{C}$ ) in eight patients. Local herpes infection was noted in 17 patients (oral 14, dermal three) and disseminated skin lesions had occurred in a 2 month old infant. The distribution of the mucocutaneous lesions was typical of herpes simplex in all cases and there was no clinical evidence of varicella. Central nervous system signs, which included alteration in the level of consciousness, convulsions, irritability, and hypotonia were noted in 16 patients. Hepatomegaly occurred in 13 patients and in most the liver was firm in consistency. Eleven children had clinical evidence of pneumonia. Bleeding manifestations, which included epistaxis, melaena, and bleeding from injection sites were noted in four children. The survival times ranged from a few hours to 25 days (mean 6.43 days).

\section{Investigations}

Sixteen patients had a haemoglobin concentration of less than $10 \mathrm{gm} / \mathrm{dl}$ (mean (SD) 8.9 (2) gm/dl). There was a wide range in total while cell count-from $4 \times 10^{9} / 1$ to $35 \times 10^{9} / 1$ (mean (SD) $\left.11 \cdot 3(9 \cdot 1) \times 10^{9} / 1\right)$. Hyponatraemia (serum sodium less than $130 \mathrm{mmol} / \mathrm{l}$ ) was noted in nine patients (mean (SD) $131(6 \cdot 4)$ $\mathrm{mmol} / \mathrm{l}$ ). Cerebrospinal fluid examination done in 12 children was normal in all. The prothrombin index was below $70 \%$ in 10 of 12 children in whom it was estimated (mean (SD) $59.2(28 \cdot 8) \%$ ). Blood cultures taken in all patients yielded positive results in seven-Staphylococcus aureus in three and Salmonella typhi, Pseudomonas aeruginosa, Klebsiella pneumonia and Escherichia coli in one each. Viral studies were not done.

\section{Pathology}

Pathological diagnosis was made on routine light microscopy alone without the use of specialised techniques such as immunoperoxidase staining or electron microscopy. In five cases the diagnosis was established on the basis of post mortem liver biopsy and in 15 cases on necropsy findings.

Light microscopic diagnosis depended on the finding of characteristic intranuclear inclusion bodies in cells infected by the virus. These are associated with epithelial ulceration or with focal necrotic lesions in parenchyma. Although the clinical diagnosis was not in doubt, it must be pointed out that herpesvirus hominis type 1 (herpes simplex), and herpesvirus varicella and zoster produce histopathological lesions which are indistinguishable on light microscopy.

The diagnostic lesion induced consists of a focus of coagulation necrosis usually associated with a peripheral haemorrhagic zone. Inflammatory cell response is absent or negligible and affected cells contain intranuclear amphophilic to eosinophilic inclusion bodies. ${ }^{1011}$

\section{Biopsy findings}

The five liver biopsies all showed typical foci of necrosis with viral intranuclear inclusions within peripheral hepatocytes. All biopsies showed fatty degeneration of hepatocytes. This was predominantly macrovesicular in type. Minimal inflammatory cells were noted in portal tracts and in association with the necrotic lesions.

\section{Necropsy findings (Table 1)}

Liver. In eight of the 15 cases diagnosis of disseminated herpesvirus infection was made at the time of necropsy on the basis of the macroscopic appearance of the liver. Affected livers showed multiple focal necroses, seen as punctate yellow-white foci, each encircled by a narrow haemorrhagic zone. Liver weight was increased in all 13 cases in which it was recorded. The liver was the only organ which showed macroscopic evidence of herpes virus infection.

Histology confirmed the presence of characteristic herpetic lesions in 13 of the 14 cases examined. Fatty degeneration was noted in 11 cases and this varied from mild to severe. In no case was there severe inflammatory cell response in either portal areas or parenchyma.

Case 7 showed macroscopic and microscopic evidence of liver abscesses which were considered to be of probable amoebic origin. No amoebic

Table 1 Necropsy findings in 15 cases of disseminated herpes simplex infection

\begin{tabular}{|c|c|c|}
\hline $\begin{array}{l}\text { Case } \\
\text { No }\end{array}$ & $\begin{array}{l}\text { Age } \\
\text { (months) }\end{array}$ & Cause of death* \\
\hline 1 & 15 & $\begin{array}{l}\text { Suppurative bronchopneumonia with } \\
\text { laryngotracheobronchitis }\end{array}$ \\
\hline 2 & 20 & $\begin{array}{l}\text { Gastroenteritis } \\
\text { Early bronchopneumonia } \\
\text { Malnutrition }\end{array}$ \\
\hline 3 & 18 & $\begin{array}{l}\text { Lobar pneumonia with empyema } \\
\text { Myocarditis of uncertain aetiology }\end{array}$ \\
\hline 4 & 12 & Interstitial nephritis \\
\hline 5 & 20 & Gastric erosions-haematemesis \\
\hline 6 & 48 & Gastroenteritis \\
\hline 7 & 11 & $\begin{array}{l}\text { Cerebral sinus thrombosis with subarachnoid } \\
\text { haemorrhage } \\
\text { Liver abscesses (? amoebic) }\end{array}$ \\
\hline 8 & 16 & Bronchopneumonia \\
\hline 9 & 13 & Suppurative bronchopneumonia with abscesses \\
\hline 10 & 18 & $\begin{array}{l}\text { Suppurative bronchopneumonia with empyema. } \\
\text { pericarditis and mediastinitis }\end{array}$ \\
\hline 11 & 24 & $\begin{array}{l}\text { Malnutrition } \\
\text { Bronchopneumonia }\end{array}$ \\
\hline 12 & 13 & Bronchopneumonia \\
\hline 13 & 8 & Malnutrition \\
\hline 14 & 36 & Bronchopneumonia \\
\hline 15 & 2 & Bronchopneumonia \\
\hline
\end{tabular}

*All cases had evidence of disseminated herpes simplex infection. 
trophozoites or herpetic inclusions were identified in these necrotic lesions.

Adrenal glands. Although adrenal glands failed to show macroscopic diagnostic features, focal necroses were noted in 11 of 13 cases examined histologically.

Brain. In no case did the brain show macroscopic abnormality beyond mild congestion and oedema. In case 11 representative sections from cerebral hemispheres showed evidence of encephalitis. Histopathological changes were subtle and were limited to the presence of intranuclear inclusions in scattered degenerate astrocytes, with small numbers of associated reactive gemistocytic astrocytes. No meningeal reaction was noted and there were no other histologic indications of central nervous system infection. ${ }^{12}$

Lungs. Histology was available in 14 cases and pulmonary infection was found in 12 . All showed evidence of bacterial infection, this being bronchopneumonia of varying severity in all but one where there was a left lower lobe pneumonia with empyema. In three cases bronchopneumonia was severe and confluent with areas of suppuration, one having associated ulcerative tracheobronchitis. Cases 6 and 15 showed necrotising bronchiolitis and focal necroses characteristic of herpes virus infection with identifiable intranuclear inclusions. Two other cases showed areas of necrotising bronchopneumonia but no definite intranuclear inclusions could be found on light microscopy.

Oropharyngeal. Ulceration of lips, and either the tongue or buccal mucosa, or both was noted in 10 cases. Herpes virus inclusions were noted in epithelial cells adjacent to ulcers in seven cases. Concomitant Candidal infection was found in three cases. In two cases oropharyngeal ulceration was extensive and in one of these the ulceration extended from pharynx to the lower end of the oesophagus.

Oesophagus. Ulcerative oesophagitis was noted in five cases; viral inclusions were identified in three cases; and in two cases there was concomitant candidal infection.

Stomach. One case had terminal haematemesis resulting from active gastric erosions of uncertain aetiology.

Intestine. Two cases showed evidence of gastroenteritis. One of these showed small ulcers in both small intestine and colon but histological features
Table 2 Useful criteria for diagnosing disseminated herpes infection

\begin{tabular}{ll}
\hline Predisposing condition & Malnutrition \\
& Post measles state \\
Clinico-pathological features & Local herpes infection \\
& Encephalopathy \\
& Enlarging hepatomegaly \\
& Deteriorating pneumonia \\
& Low prothrombin index \\
& Liver biopsy (if no bleeding disorder) \\
\hline
\end{tabular}

were not specific. Microbiological cultures are not available.

Thymus. The thymus was examined histologically in six cases; all showed severe stress involution.

Submandibular salivary gland. The only case sampled showed diffuse cytomegalovirus sialitis.

Conclusion. Results from this necropsy study suggested a number of criteria which could be helpful in the diagnosis of disseminating herpes simplex infection in children particularly at risk. These are given in Table 2.

Prospective pilot study. This was conducted in five patients who had the predisposing conditions of malnutrition and the post measles state, togethero with the clinical criteria of local herpes, encephalopathy, enlarging hepatomegaly, and deteriorating pneumonia. No bleeding tendency was present, presumably because diagnosis was entertained in the early stage of the disease. Liver biopsy was performed and specific antiviral treatment commenced. The details are shown in Table 3.

\section{Discussion}

We undertook a retrospective analysis of 20 patients with disseminated herpes simplex virus infection diagnosed at necropsy to derive useful clinical criteria to aid us in diagnosing dissemination early on in the course of the disease. The clinical and pathological features have been outlined in detail. Although the clinical picture of disseminated herpes has been alluded to by others, ${ }^{3}$ we attempted to refine these criteria by basing them on local necropsy material. We used these together with the most consistent pathological findings (in the liver) to make an early diagnosis and, thereafter, to treat promptly so as to reduce high morbidity and mortality associated with this disease.

The data extracted from the necropsy study suggested that disseminated herpes infection was likely in the presence of malnutrition and post 


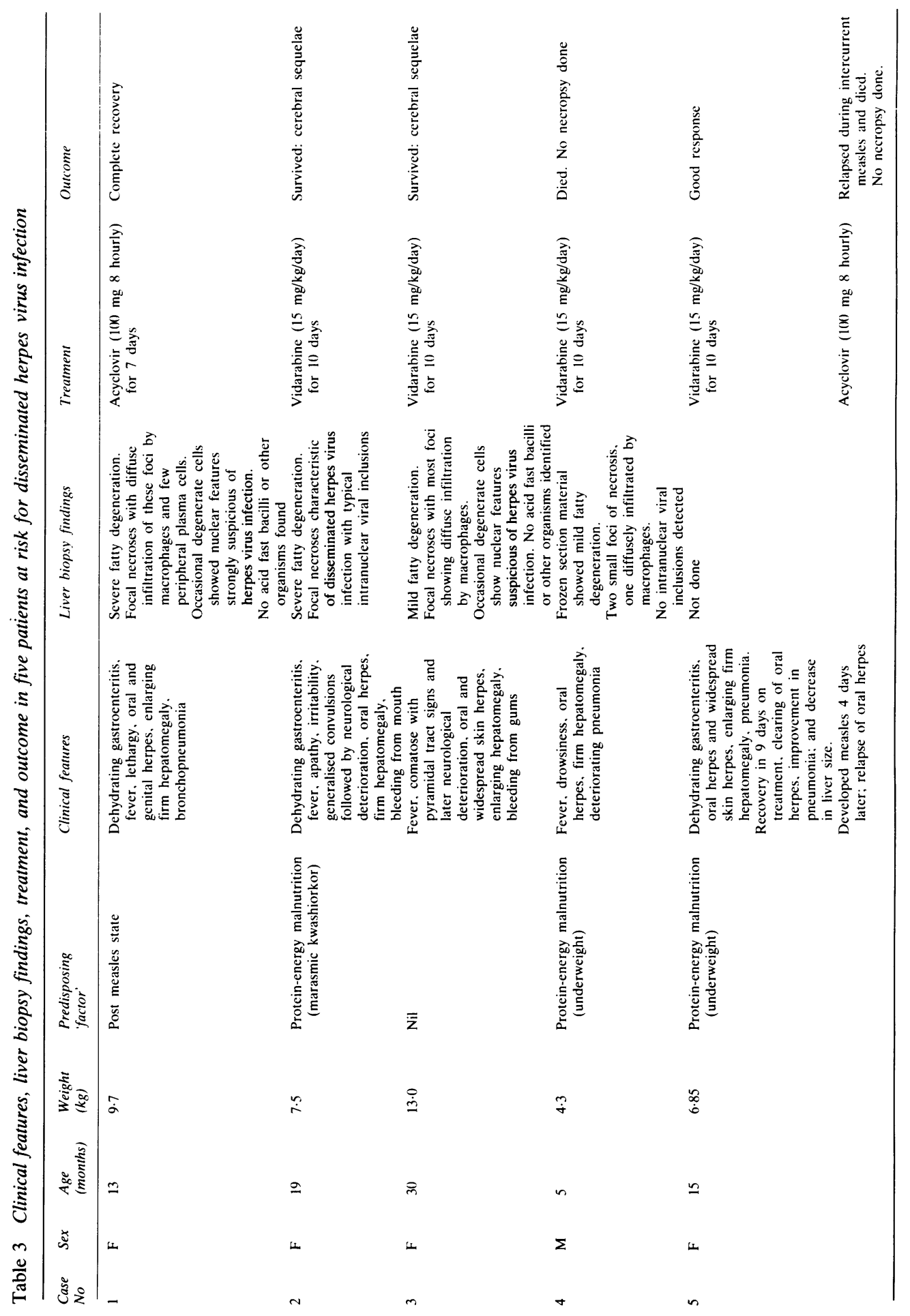


measles state. In these situations local herpes infection became widespread resulting in encephalopathy, enlarging hepatomegaly, and deteriorating pneumonia. The frequency of neurological signs and symptoms was not matched by corresponding histopathological evidence of encephalitis at necropsy. This could reflect the problems of nonrepresentative brain sampling. Clinical encephalopathy, however, may have been caused by hypoxaemia due to pneumonia, hepatic dysfunction, or metabolic abnormalities due to disseminated herpes. The limitations of the findings obtained in the necropsy study were that they would reflect the features of the most seriously affected patients and might be inappropriate or irrelevant in the clinical situation. In monitoring the sick child with local herpes, early signs of dissemination could be more subtle and the criteria established by us simply indicate a preterminal state. Treatment at this point would be less likely to succeed. We successfully employed these criteria, however, in a prospective pilot study of five patients. The presence of all or some of these criteria enabled us to suspect dissemination and reinforce the diagnosis by percutaneous liver biopsy. The high incidence of a prolonged prothrombin time seen in our necropsy study (10 out of 12) was not encountered in the prospective analysis which was fortuitous and fortunate as liver biopsy could be undertaken and served as the centrepiece of diagnosis. A possible explanation for the normal prothrombin index in the pilot study is that we may have diagnosed the disease early in its evolution.

Although only one liver biopsy in the small series of prospectively studied cases showed unequivocal evidence of herpes virus infection, the other three cases showed basic pathological lesions strongly suspicious of this condition. More sophisticated methods of diagnosis should be useful for confirmation. Specific immunoperoxidase staining is indicated and at the time of liver biopsy a separate glutaraldehyde fixed core of tissue should be submitted for electron microscopy. Frozen section, as shown by case 4 , has not proved satisfactory, largely because of the limited number of sections obtained.

The macrophage response in three of the patients seems unusual for disseminated herpes virus lesions but histological variations of the lesions have been described. A case report of an adult with herpes simplex dissemination in the liver illustrates focal necroses surrounded by dense infiltrates of neutrophils and macrophages. ${ }^{13}$

The results of treatment were not spectacular but promising as there were four survivors of five patients studied. One subsequently died of measles and recrudescence of herpes. Necropsy was refused in this patient. It is evident from this last case that $\frac{\rho}{\mathcal{L}}$ antiviral treatment (vidarabine) merely controlled but did not eliminate herpes virus infection.

Using the suggested criteria for diagnosis of $\stackrel{5}{?}$ disseminated herpes simplex infection in the im- $\frac{0}{0}$ munocompromised host would be very useful in developing countries and may be of some benefit in $\frac{\bar{s}}{\overrightarrow{0}}$ other communities as well, for example after organ $\stackrel{\varnothing}{\stackrel{D}{\varrho}}$ transplantation. To undertake double blind placebo-controlled studies of acyclovir and other $\vec{\circ}$ newer antivirals, strict criteria for diagnosis of $\stackrel{-}{-}$ disseminated herpes infection will be required and $\vec{\omega}$ perhaps the features given here may serve this $\stackrel{\mathscr{\omega}}{\sigma}$ function.

HMC is in receipt of a South African Medical Research Council grant.

\section{References}

1 Zuelzer WW, Stulberg CS. Herpes simplex virus as the cause of fulminating visceral disease and hepatitis in infancy. Am J Dis Child 1952;83:421-39.

2 Kipps A, Becker WB, Wainwright J, McKenzie D. Fatal disseminated primary herpes virus infection in children: $\mathbb{D}$ epidemiology based on 93 non-neonatal cases. $S$ Afr Med $J$ 1967:41:647-51.

${ }^{3}$ Becker WB, Kipps A. McKenzie D. Disseminated herpes simplex virus infection: its pathogenesis based on virological ang $\overrightarrow{0}$ pathological studies in 33 cases. Am J Dis Child 1968:115:1-80

4 McKenzie D, Hansen JDL, ,Becker W. Herpes simplex virł infection: dissemination is associated with malnutrition. $\operatorname{Ar} \$$ Dis Child 1959;34:250-6.

5 Becker W, du T Naudé W, Kipps A, McKenzic D. Virus studies in disseminated herpes simplex infections-association with malnutrition in children. $S$ Afr Med $J$ 1963;37:74-6.

6 Templeton AC. Generalised herpes simplex in malnourished children. J Clin Pathol 1970;23:24-30.

Orren A, Kipps A, Moodie JW, Beatty DW, Dowdle EB. McIntyre JP. Increased susceptibility of herpes simplex virus infection in children with acute measles. Infect Immun $1981 ; 31: 1-6$.

${ }^{\star}$ Montgomerie JZ, Becroft DMO, Croxson MC, Doak PB Herpes simplex virus infection after renal transplant. Lancet 1969;ii:867-71.

9 Taylor RJ, Saul SH. Dowling JN, Hakala TR, Peel RL, Ho M. Primary disseminated herpes simplex infection with fulminant 3 hepatitis following renal transplantation. Arch Intern Med 1981;141:1519-21.

11 Strano AJ. In: Binford CH, Conner DH, eds. Pathology of tropical and extraordinary diseases: an atlas. Vol. 1. Washington: 음 Armed Forces Institutc of Pathology. 1976:58.

1 Strano AJ. Light microscopy of selected viral diseases (morphology of viral inclusion bodies). Pathol Annu 1976;11: ․ㅡ․ 53-75.

12 Strano AJ. In: Binford CH, Conner DH, eds. Pathology of $\sigma$ tropical and extraordinary diseases: an atlas. Vol 1. Washington: N Armed Forces Institute of Pathology, 1976:70.

13 Flewett TH, Parker RGF, Philip WM. Acute hepatitis duc to $\mathrm{W}$ herpes simplex virus in an adult. J Clin Pathol 1969;22:60-6. ర

Correspondence to Professor H M Coovadia. Department of Paediatrics and Child Health, PO Box 17039. Congella 4013, South Africa.

Received 18 May 1984 